\title{
Effect of nurse' Managers Professionalism Behavior on Their Job Satisfaction at Assuit University Hospital
}

\author{
Somia Mohamed Abdel Aziz ${ }^{1}$, Sahar Mohamed Morsy ${ }^{2}$ \& Nahed Shawkat Abo El-magd ${ }^{3}$. \\ 1. Demonstrator in Nursing Administration Department, Faculty of Nursing, Assuit University, Egypt. \\ 2. Prof of Nursing Administration, Faculty of Nursing, Assiut University, Egypt. \\ 3. Assist. Prof of Nursing Administration, Faculty of Nursing, Assiut University, Egypt.
}

\begin{abstract}
Introduction: Professionalism is one of the soft skills which allows to be efficiently related to other, improve personal relations and lead to better work performance and fulfillment. Aim: Investigate the effect of professionalism behavior on job satisfaction of nurse managers at Assuit University hospital. Research design: A descriptive correlational design was used. Setting: This study was conducted at Assuit University Hospital. Subjects: the study subject consisted of (170) Nurse Managers classified to nursing directors, supervisors and head nurses working at Assuit University Hospital. Tools: the data collected through self - administered questionnaire which includes personal characteristics data, Behavioral inventory form for professionalism in nursing scale (BIPN) and Minnesota satisfaction questionnaire. Results: The highest mean scores regarding to professionalism behaviors domains were related to Self-regulation \& autonomy, Competence and continuing education $(4.59 \pm 2.03)$, (4.21 \pm 2.45)respectively. The highest mean scores regarding to job satisfaction factors were related to Communication $\&$ relationship in the work and the working conditions $(\mathbf{2 3 . 9 1} \pm \mathbf{4 . 7 0}),(\mathbf{1 9 . 2 8} \pm \mathbf{4 . 2 7})$ respectively. Conclusions: There is significant positive correlations between professionalism behavior and job satisfaction among nurse managers. Recommendations: Develop and implement continues educational programs for nurse managers that will affect the professional behavior of them.
\end{abstract}

\section{Key words: Professionalism Behavior, Job Satisfaction \& Nurse Managers.}

\section{Introduction}

Health care institutions desire nurse managers to be responsible, accountable, ethical, and team oriented, and to have strong communication, between-people, and problem solving skills. bind these skills up all together and will have got professionalism (Grant, 2014).

Nurse Managers give power to nurses to develop their performance and to intend motivating changes to their workplace. The practice of professional behaviors via the nurse managers are very important to assist an organizational culture that generate a helpful workplace for nurses (Eneh et al., 2012).

nurse leaders, nurse managers are accountable for increasing career development opportunities and improving professionalism for nurses. Experimental research has proposed that the working surroundings and work satisfaction has positive impact on progress and professional practice (Palmer, 2014). Working surroundings and job satisfaction have often been showed as the most significant predictors for nurses' plan to maintain working at an institution and those are related to nurse managers' behaviors . Nurse managers behaviors have a strong influence on professional advancement(Keys, 2014).

Dikmen et al., (2016) defined the professionalism as the conduct, aims, or traits that describe or mark a career or a qualified person". It is also the recognition and acceptance of the knowledge, skills, and values necessary to those who have been trained in that career.

Irvine et al., (2007) confirmed that professional behaviors that added to nursing professionalism are considered an important element of nursing leadership within a international framework. The importance of advancing worldwide information has been acknowledged in nursing, and for the reason that various healthcare issues cross global boundaries, that want for a global exchange of information and evidence is better than ever.

It is very vital for nurses to project the qualities and standards of professionalism in the nursing career. These consist of educational preparation, managing and doing research, reading publications, providing community trainings, participating in professional Organizations, adhering to nursing codes, exhibiting autonomy, and viewing competence with sufficient theoretical knowledge and continuing learning (Adıguzel, et al., 2011).

Understanding how to get better job satisfaction as an outcome is very important as it relates to worker health, working done and getting a lot done, and job performance (Whitman et al., 2010). 
In addition to , it can be assumed that efficient improvement of professional identity can contribute to individual autonomy, professional self-confidence, and able to communicate effectively, all of which are possible to raise job satisfaction (Tanang \& Abu, (2014).

Lane et al., ( 2010) said that Job satisfaction is influenced by different factors regarding the work surroundings and the individuals. The job satisfaction of staff is influenced by various components, for example socio demographic variables, the physical structure of the workplace, and wages .There is another factor influencing work satisfaction is professionalism. Professionalism is viewing commitment to the profession (Hwang et al., 2009).

\section{Significance of the study}

Nowadays many studies were published in professional articles and journals nationally and internationally which focused in assessing the effect of professionalism behavior on job satisfaction such as Çelik \& Hisar (2012) study of the influence of the professionalism behavior of nurses working in health institutions on job satisfaction. Also nursing professionalism has become an issue of international importance. The job satisfaction of nurse managers was found to be low or medium in various studies conducted in Turkey (Hampton et al., 2004). Also, Hwang et al., (2009) concluded that the job satisfaction level of nurse managers lead to increase the professionalism behavior. Nursing professionalism reflects the manner in which head nurses view their work and is a guide to nurses' behavior in practice to ensure patient safety and quality care. If nurses have a higher commitment to their profession, they are more satisfied with their job (Lu et al., 2005).

\section{Aim of the study}

The present study aims to

Investigate the effect of professionalism behavior on job satisfaction of nurse managers at Assuit University Hospital.

\section{Research questions}

To fulfill the aim of the present study, the following research questions are formulated:

Q1: What are the professional behavior levels nurse managers at Assuit University Hospital?

Q2: What are the job satisfaction levels of nurse managers at Assuit University Hospital?

Q3: What are the effects of professionalism behavior on job satisfaction of nurse managers at Assuit University Hospital?
Q4: What are the factors affecting professionalism behavior of nurse managers at Assuit University Hospital?

Q5: Are there relation among personal characteristics, professionalism behavior and job satisfaction among studied nurse managers?

\section{Subjects \& Method \\ 1. Technical design}

This design includes the research design, setting, subjects, and data collection tools.

Study design

A descriptive correlational research design was used on the present study.

\section{Study setting}

The study was conducted at Assiut University Hospital which includes (Main Hospital No $=47$, Pediatric No $=19$, Women's health No $=20$, Urology and Nephrology No =18, Neurology and Psychiatric No $=22$, Rajhi- Liver No $=21$, and Orman Hospital No $=23$ ) total number $=170$.

subjects:

The study subject was comprised all nurse managers, nursing directors supervisors, and head nurses with total number(170)working at Assiut University Hospital.

Data collection tools

The data needed for the study was collected using self-administrated questionnaires, it comprised of two tools

first tool comprised two parts

Part (1): Personal data sheet

It was designed to collect personal data about nurse managers include; gender, age, unit, educational qualification, years of experience in the hospital, and the current job.

Part (II): Behavioral inventory form for professionalism in nursing scale (BIPN): it was developed by the researcher based on the tool of Miller et al., (1993) and used to assess nurse managers professionalism behavior. the researcher took 9 subscale and developed the items of every subscale so the scale become consist of(9)subscale as the following, educational preparation(3items), publication and communication(3items), research development(4items), participation in a professional organization(3items), community service(2items), competence and continuing education(9items) , theory development(6items), autonomy and selfregulation(9items), code for nurses(3item)and the researchers added two open ended questions about what are the factors affecting the professionalism behavior \& do you have other suggestion that could be added to enrich professional nursing career? 


\section{Scoring System}

The responding system was measured for each sub items by (1) for yes and (0)for no total score which equal (42); If the score ranges from (0-25) the level will be considered low(below 60\%), If the score ranges from (26-42) the level will be considered high (above 60\%).

Second Tool: Minnesota satisfaction questionnaire: was developed by (Weiss et al., 1967), adopted from (Mohamed, 2001) and used to measure nurse' managers job satisfaction and it consists of (4)subscale which include the nature of the work(4 items), communication and relationship in the work(10 items),rules and regulation of the hospital(5 items), the working condition( 8 items), responses will be measured on3pointslikert scale which ranged from(1) for dissatisfied, (2) for I cannot decide whether you are satisfied or not, and(3) for satisfied.

\section{Scoring System}

The responding system was measured by3points likert scale which ranged from(1) for dissatisfied, (2) for I cannot decide whether you are satisfied or not, and(3) for satisfied, total score which equal (81); If the score ranges from (27-48) the level would be considered dissatisfied(below 60\%), If the score ranges from (49-81) the level would be considered satisfied(above $60 \%$ ).

\section{Administrative design}

Official approval to carry out this study obtained from the Dean of Faculty of Nursing, Assuit University, Director of Assuit University Hospitals, Nursing Directors, and Head of each department to collect the necessary data.

\section{2) Ethical considerations}

Study proposal was approved from Ethical Committee in the Faculty of Nursing, Oral agreement was taken from the participants. Confidentiality of obtained data was assured, and the purpose, nature, and the aim of the study was explained to all participants before starting of data collection.

\section{Operational design}

1) Preparatory phase

It includes reviewing the available literatures concerning the topic of the study, Arabic translation of the study tool was done. It took about three months from August to October 2018.The BIPN questionnaire was checked by 5 experts 3from Nursing Administration Department and 2 from Community Health Nursing Department to ensure face validity and reliability was checked through a pilot study and no modification was done.

\section{2) Pilot study}

A pilot study was carried out to assess tool clarity, understandability, and applicability of the research tools. Additionally, to identify problems that might be encountered during the actual data collection. It applied on $(10 \%)$ from total sample (17) nurse managers from different units of the hospitals and conducted through a week from 5- 11/12/ 2018. Data collected from the pilot study was analyzed and no changes were done for the study tools, thus the nurse managers who share in the pilot study were included in the study pilot.

The study tools were tested for its reliability by using Crombach's Alpha Co- efficient test, it was $(\mathrm{a}=$ 0.743) for Behavioral inventory form for professionalism in nursing scale $(\mathrm{BIPN})$ and $(\mathrm{a}=$ 0.703) for Minnesota Satisfaction Questionnaire.

\section{3) field work}

The study tool was given to the participated nurse managers to be filling through self- administered questionnaire. Each participant took about thirteen minutes to fulfill the questionnaire. The whole period for data collection took about three months from November 2018 to January 2019.

\section{4-Statistical analysis}

Data entry and data were done using SPSS version 19 (Statistical Package for Social Science). Data were presented as number, percentage, mean, median and standard deviation. Independent samples t-test was used to compare quantitative variables between two groups and ANOVA test was used for more than two groups. Pearson correlation was done to measure correlation between quantitative variables. P-value considered statistically significant when $\mathrm{P}<0.05$. 


\section{Results}

Table (1): Distribution of personal characteristics of the studied nurse managers at Assuit University Hospital (n=170).

\begin{tabular}{|c|c|c|}
\hline Items & No. (170) & $\%$ \\
\hline \multicolumn{3}{|l|}{ Hospital: } \\
\hline Main Hospital & 47 & 27.6 \\
\hline Women Hospital & 20 & 11.8 \\
\hline Pediatric Hospital & 19 & 11.2 \\
\hline Orman Hospital & 23 & 13.5 \\
\hline El-Ragehy Hospital & 21 & 12.4 \\
\hline Neurology Hospital & 22 & 12.9 \\
\hline Urology Hospital & 18 & 10.6 \\
\hline \multicolumn{3}{|l|}{ Gender: } \\
\hline Female & 161 & 94.7 \\
\hline Male & 9 & 5.3 \\
\hline \multicolumn{3}{|l|}{ Age: (years) } \\
\hline$<30$ & 48 & 28.2 \\
\hline $30-<40$ & 77 & 45.3 \\
\hline$\geq 40$ & 45 & 26.5 \\
\hline Mean \pm SD (Range) & \multicolumn{2}{|c|}{$35.41 \pm 7.38(24.0-58.0$} \\
\hline \multicolumn{3}{|l|}{ Education: } \\
\hline Bachelor of Nursing & 117 & 68.8 \\
\hline Diploma Degree & 6 & 3.5 \\
\hline Master Degree & 42 & 24.7 \\
\hline Doctorate Degree & 5 & 2.9 \\
\hline \multicolumn{3}{|l|}{ Years of experience: } \\
\hline$<10$ & 66 & 38.8 \\
\hline $10-15$ & 44 & 25.9 \\
\hline$>15$ & 60 & 35.3 \\
\hline Mean \pm SD (Range) & \multicolumn{2}{|c|}{$12.67 \pm 7.29(1.0-32.0)$} \\
\hline \multicolumn{3}{|l|}{ Current Job: } \\
\hline Head Nurse & 147 & 86.5 \\
\hline Supervisor & 16 & 9.4 \\
\hline Nurse manager & 7 & 4.1 \\
\hline
\end{tabular}

Table (2): level of Professionalism behaviors domains as perceived by the studied nurse managers at Assuit University Hospital (n=170).

\begin{tabular}{|l|c|c|c|c|}
\hline \multirow{2}{*}{\multicolumn{1}{|c|}{ Professionalism behaviors domains }} & \multicolumn{2}{c|}{ Low } & \multicolumn{2}{c|}{ High } \\
\cline { 2 - 5 } & No. & $\mathbf{\%}$ & No. & $\mathbf{\%}$ \\
\hline Educational preparation & 165 & $\mathbf{9 7 . 1}$ & 5 & 2.9 \\
\hline Publication and communication & 125 & 73.5 & 45 & 26.5 \\
\hline Research development & 131 & 77.1 & 39 & 22.9 \\
\hline Participation in professional organization & 165 & $\mathbf{9 7 . 1}$ & 5 & 2.9 \\
\hline Community services & 139 & $\mathbf{8 1 . 8}$ & 31 & 18.2 \\
\hline Competence and continuing education & 98 & 57.6 & 72 & 42.4 \\
\hline Theory development & 50 & 29.4 & 120 & $\mathbf{7 0 . 6}$ \\
\hline Self-regulation \& autonomy & 114 & 67.1 & 56 & 32.9 \\
\hline Code for nurses & 70 & 41.2 & 100 & $\mathbf{5 8 . 8}$ \\
\hline Total Professional behaviors & 141 & $\mathbf{8 2 . 9}$ & 29 & 17.1 \\
\hline
\end{tabular}


Table (3): level of job satisfaction domains as perceived by the studied nurse managers at Assuit University Hospital (n=170).

\begin{tabular}{|l|c|c|c|c|}
\hline \multirow{2}{*}{ job satisfaction domains } & \multicolumn{2}{c|}{ Dissatisfied } & \multicolumn{2}{c|}{ Satisfied } \\
\cline { 2 - 5 } & No. & $\mathbf{\%}$ & No. & $\mathbf{\%}$ \\
\hline The nature of work & 26 & 15.3 & 144 & $\mathbf{8 4 . 7}$ \\
\hline Communication \& relationship in the work & 16 & 9.4 & 154 & $\mathbf{9 0 . 6}$ \\
\hline Rules \& regulation of the hospital & 60 & $\mathbf{3 5 . 3}$ & 110 & 64.7 \\
\hline The working conditions & 34 & 20.0 & 136 & 80.0 \\
\hline Total Job satisfaction & 20 & 11.8 & 150 & 88.2 \\
\hline
\end{tabular}

Table (4): Distribution of nurse managers opinions about Factors affecting the professionalism behavior among nurse managers at Assuit University Hospital (n=170).

\begin{tabular}{|l|c|c|}
\hline \multicolumn{1}{|c|}{ Factors affecting the professionalism behavior } & No. (170) & \% \\
\hline Salary and moral factor & 40 & $\mathbf{2 3 . 6}$ \\
\hline Social and Psychological factors & 28 & $\mathbf{1 6 . 5}$ \\
\hline Years of experience & 50 & $\mathbf{2 9 . 5}$ \\
\hline workload in the workplace is high due to shortage of the staff & 15 & 8.8 \\
\hline There weren't development in laws\& regulation concerning nursing & 10 & 5.8 \\
\hline
\end{tabular}

Table (5): Relationship among personal characteristics, professionalism behaviors and job satisfaction as perceived by the studied nurse managers at Assuit University Hospital (n=170).

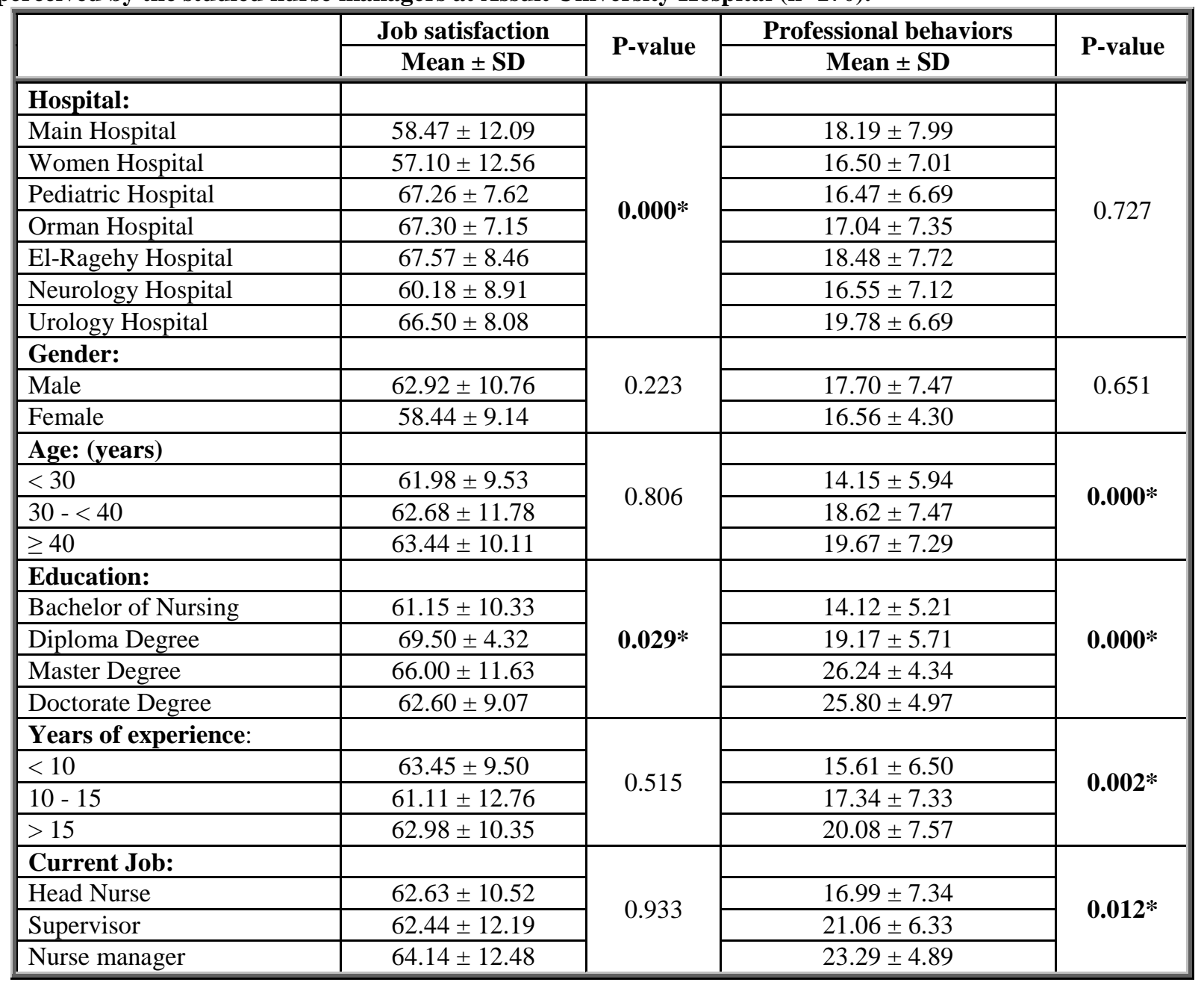


Table (6): Mean score of professionalism behaviors and its domains as perceived by the studied nurse managers at Assuit University Hospital (n=170).

\begin{tabular}{|l|c|c|}
\hline \multicolumn{1}{|c|}{ Professional behaviors domains } & Mean \pm SD & Median (Range) \\
\hline Educational preparation & $0.34 \pm 0.53$ & $0.0(0.0-2.0)$ \\
\hline Publication and communication & $0.66 \pm 1.01$ & $0.0(0.0-3.0)$ \\
\hline Research development & $1.31 \pm 1.43$ & $1.0(0.0-4.0)$ \\
\hline Participation in professional organization & $0.25 \pm 0.50$ & $0.0(0.0-2.0)$ \\
\hline Community services & $0.61 \pm 0.78$ & $0.0(0.0-2.0)$ \\
\hline Competence and continuing education & $\mathbf{4 . 2 1} \pm \mathbf{2 . 4 5}$ & $4.0(0.0-12.0)$ \\
\hline Theory development & $\mathbf{3 . 9 1} \pm \mathbf{1 . 1 7}$ & $4.0(1.0-6.0)$ \\
\hline Self-regulation \& autonomy & $\mathbf{4 . 5 9} \pm \mathbf{2 . 0 3}$ & $5.0(0.0-8.0)$ \\
\hline Code for nurses & $1.76 \pm 1.08$ & $2.0(0.0-3.0)$ \\
\hline Total Professional behaviors & $17.64 \pm 7.33$ & $17.0(1.0-34.0)$ \\
\hline
\end{tabular}

Table (7): Mean score of job satisfaction factors as perceived by the studied nurse managers at Assuit University Hospital (n=170).

\begin{tabular}{|l|c|c|}
\hline \multicolumn{1}{|c|}{ Job satisfaction factors } & Mean \pm SD & Median (Range) \\
\hline The nature of work & $9.66 \pm 2.32$ & $10.0(4.0-12.0)$ \\
\hline Communication \& relationship in the work & $\mathbf{2 3 . 9 1} \pm \mathbf{4 . 7 0}$ & $25.0(10.0-30.0)$ \\
\hline Rules \& regulation of the hospital & $9.83 \pm 2.99$ & $10.0(5.0-15.0)$ \\
\hline The working conditions & $\mathbf{1 9 . 2 8} \pm \mathbf{4 . 2 7}$ & $20.0(9.0-24.0)$ \\
\hline Total job satisfaction & $62.68 \pm 10.70$ & $64.5(36.0-81.0)$ \\
\hline
\end{tabular}

Table (8): Distribution of suggestions to enrich professionalism behavior of nursing careers as perceived by the studied nurse managers at Assuit University Hospital ( $n=170)$.

\begin{tabular}{|l|c|c|}
\hline \multicolumn{1}{|c|}{ Suggestions to enrich professionalism behavior } & No. (170) & \% \\
\hline $\begin{array}{l}\text { know what is new regarding the field of specialization in } \\
\text { addition to increasing the training courses }\end{array}$ & 64 & $\mathbf{3 7 . 6}$ \\
\hline Reward, promotion and salary structure need to improve & 28 & 16.5 \\
\hline $\begin{array}{l}\text { Provide more support services for nurses and increase the } \\
\text { number of staff nurse. }\end{array}$ & 7 & 4.1 \\
\hline Nurses rules and regulation need to improve & 3 & 1.8 \\
\hline
\end{tabular}

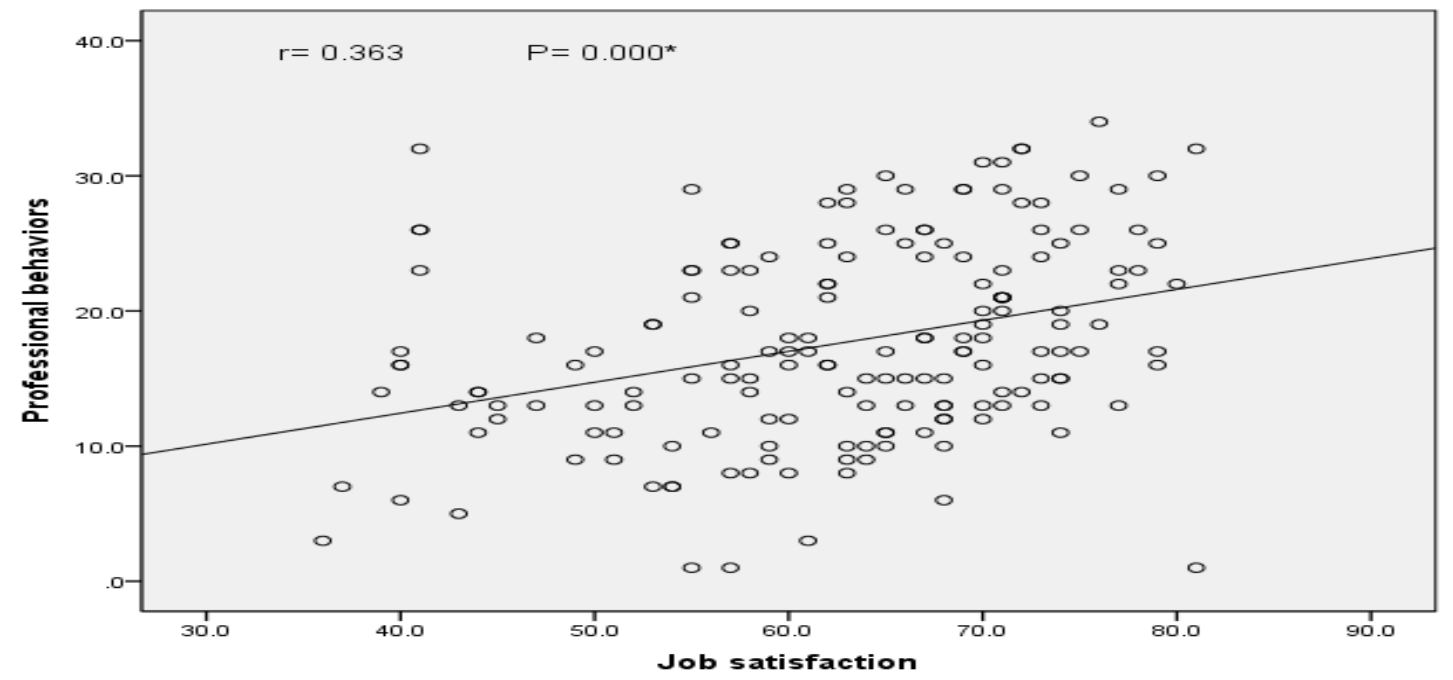

Figure (1): Correlation of professional behaviors with job satisfaction as perceived by the studied nurse managers at Assuit University Hospital (n=170). 
Table (1): Illustrated that, more than two thirds of nurse managers having a Bachelor degree in nursing science $(68.8 \%)$, The vast majority of the study subject were females $(94.7 \%)$ and about $(27.6 \%)$ of them working at the Main Assuit University Hospitals, more than one third of them have years of experience range <10years $(38.8 \%)$, the majority of them were head nurses $(86.5 \%)$ and about $(45.3 \%)$ of them aged between $30-<40$ Years.

Table (2): Illustrated that, the highest percent of nurse managers reported high level of professionalism behavior toward theory development $\mathbf{( 7 0 . 6 \% )}$ followed by code for nurses $(58.8 \%)$.On the other hand, the highest percent of nurse managers reported low level of professionalism behavior toward educational preparation and participation in professional organization $(97.1 \%)$, followed by community services $(81.8 \%)$. Finally the highest percent of nurse managers as regard to total professionalism behavior were low $(82.9 \%)$.

Table (3): Illustrated that, the highest percent of nurse managers had high level of satisfaction toward communication \&relationship in the work (90.6\%), followed by the working condition $(80.0 \%)$, followed by the nature of the work $(84.7 \%)$. On the other hand, the highest percent of nurse managers had low level of satisfaction toward rules\& regulation in the hospital $(35.3 \%)$. Finally the highest percent of nurse managers reported high level of satisfaction $(88.2 \%)$ for the total job satisfaction domains.

Table (4): Showed that the factor which affecting the professionalism behavior as perceived by the studied nurse managers were years of experience, followed by salary and moral factor, Social and Psychological factors $(\mathbf{2 9 . 5 \%}-\mathbf{2 3 . 6 \%}-\mathbf{1 6 . 5 \%})$ respectively.

Table (5): Illustrated that, there was a relation between the professional behaviors in accordance to personal characteristic data. There was highly statistically significant relation between professional behaviors as reported by nurse managers in accordance to age, educational qualification, years of experience, current job $(0.000,0.000,0.002,0.012)$ respectively, While There was no statistically significant relation regarding to hospital and gender (0.727\&0.651) respectively. There were statistically significant relation between the job satisfaction in accordance to hospital, nurse managers qualification(0.000- 0.029) respectively. There was no statistically significant relation between job satisfaction domains as reported by nurse managers in accordance to gender, age, years of experience, current job, (0.223, 0.806, 0.515 and $0.933)$ respectively.

Table (6): Showed that, the highest mean score regarding to professionalism behaviors domains was related to Self-regulation \& autonomy $(4.59 \pm 2.03)$, followed by Competence and continuing education $(4.21 \pm 2.45)$ followed by Theory development (3.91 $\pm 1.17)$.

Table (7): Cleared that, the highest mean scores regarding to job satisfaction domains were related to communication \& relationship in the work $(23.91 \pm$ $4.70)$, followed by the working conditions (19.28 \pm 4.27).

Table (8): Depicted that, more than one third $(37.6 \%)$ of them suggest that they need to know what is new regarding the field of specialization in addition to increasing the training courses. $(16.5 \%)$ of them said that they need to improve reward, promotion and salary structure. $(4.1 \%)$ of them mentioned that they need more support services for nurses and increase the number of staff nurses, and only (1.8\%) of them said that the nurses rules and regulation need to improve.

Fig (1): Revealed that, there was a significant positive correlation between job satisfaction factors and professional behaviors domains.

\section{Discussion}

The study findings showed that, the majority of nurse managers had low level as regard to the total professionalism behavior domains (table, 2). This might be attributed to nurse managers are unaware of the importance of professionalism behaviors, its domains that they need to improve their level of professionalism behaviors and hospitals didn't support them in developing professionalism behaviors.

The study results was consistent with Dikmen et al., (2016) who stated that professional levels of nurse managers have been found to be low in professionalism studies conducted in Turkey and these results also support our study. these which inhibit the development of professional behaviors .Professionalism in nursing is delayed due to many negative factors, such as the differences between educational levels in nursing in Turkey, perception in the community about nursing as a profession, the hierarchic structures of hospitals, intense workloads, the focus of nursing on tasks, a lack of personnel and equipment, insufficient job security, low salaries, and weakness in organized labor. so that help nurse managers continue their self-development and to realize the potential of their nursing staff by developing professionalism.

The study findings showed that, the majority of the nurse managers were satisfied for total job satisfaction domains (table, 3). This might be attributed to having a good working positive environment which help them to work all the time without feeling pressured or tired also all of them like their jobs. 
The study results is consistent with Atefi et al., (2016) who found that high level of workplace environment were generated by effective communication and collaboration, and decision making promotion among nurses. These reasons lead to increase in job satisfaction and retention.

The study findings revealed that, the highest mean score regard to factors affecting the professional behaviors were years of experience and salary and moral factor (table, 4). This might be attributed to the hospital doesn't give any support or reward for nurse managers although they have excessive workload, long working hours, also they dissatisfied with salaries. These factors can resulted in resistance to development professional behaviors.

This finding was consistent with Atefi, et al., (2014) explained that inhibit the development of professional behaviors, may be due to excessive workload, long work hours, and an inadequacy of the sources provided. Also, Holmberg, et al., (2018) found that salary, promotion and reward had big effect on professionalism behavior, retention of nurses and job satisfaction. Also Watson, (2006) noted that a great deal of professionalism is learned from work experience.

The study findings revealed that, there is significant relation between professional behavior and educational qualifications, years of experience and age (table, 5). This might be attributed to that study subject who have master and doctorate degree in nursing and who had longer years of experience are more knowledgeable about new challenges, changes $\&$ information in nursing issues that contribute to professional development .

Also this finding was consistent with Watkins, (2011) \& Drennan, (2012) who reported that the core of nursing education is the master's degree, where students learn to be professional by increasing their confidence, improving cognitive functioning and developing evidence-based practice. It is essential for nurse managers to acquire higher education to maintain their professionalism and critically to support and encourage positive environment for staff nurses to obtain higher degrees. This finding was consistent with Pool et al., (2013) who mentioned that career paths for those positions are different because a nurse administrator is required to have both longer experience and higher education, so there are positive correlation between professionalism behavior and the current job.

The study findings revealed that, there is significant relation between professional behaviors and current job, the highest mean score was for nurse managers (table, 5). This might be attributed to that they are more knowledgeable about nursing issues, skillful because they have longer experience about workplace that contributes to professional development.

The study findings revealed that, there is significant relation between job satisfaction and qualification (table, 5). This might be attributed to when the nurse managers have higher education they have the more skills, information and self-confidence in their work which leads to job satisfaction.

This finding was consistent with Yarbrough, et al., (2017) who found that there was strong relation between level of education and job satisfaction, with holders of master\& doctorate degree more satisfied than bachelor holders, this nurses more knowledgeable and more skillful than nurses with bachelor degree that become more satisfied with their job.

The study findings revealed that, there is statistically significant relation between job satisfactions and hospitals (table, 5). the highest mean sore was in ElRagehy hospital \&Orman hospital; this might be attributed to these hospitals applying new system and using the electronic health system recording that makes nurse managers more satisfied with their job.

The study findings revealed that, the highest mean score regard to professional behaviors and its domains was the self-regulation and autonomy (table, 6). This might be attributed to the hospitals give nurse managers opportunity in decision making in their practice that help them to feel powerful.

This finding was consistent with Adler \& Kwon, (2013) who mentioned that self-regulation and professional autonomy considered the heart of professionalism and has effect on nurse's capacity and power, so nurse managers should have power to make their own decisions free from external pressures to achieve goals and to achieve satisfaction for them.

The study findings revealed that, the highest mean score regarding to job satisfaction was communication \&relationship in the work (table, 7). This might be attributed to that the relationships among them were good \&pleasant, all of them like their jobs and engaged in it.

This finding was consistent with Brunges \& FoleyBrinza, (2014). who mentioned that when communication among health team members about tasks and responsibilities are done well, research evidence has shown significant reduction in nurse turnover and improved job satisfaction.

From the findings of the current study, it appeared that more than one third of the study subject said that they need to know what is new regarding the field of specialization in addition to increasing the training courses to enrich professionalism behavior of nursing careers (table, 8). This might be attributed to the 
possibility that they don't attend any conference or any special courses to learn what is new in their field.

This finding was consistent with Ghadirian, et al., (2014) who found that professionalism behavior can be developed through professional training in formal programs that can be provided with specific workshops and courses of training development modules. Every training program should be designed to meet the expectations concerning professionalization.

The study findings showed that, there was highly positive correlation with highly statistical significance correlation between professional behavior\& job satisfaction (fig, 1). This might be attributed to that when nurse managers use professional behavior in their work, the roles of nursing will expand and, as a result, work environment will also change. The quality of nursing application in the hospital will increase, and the safety of the employees and patient care will be enhanced. Positive developments directed at the patients and the employees will also increase job satisfaction.

In the same line Celik \& Hisar (2012) who mentioned that Professionalism and job satisfaction were found to have a positive relation. The supportiveness of management and the adequacy of resources were positively correlated with quality of care, positive feelings toward their job, and negatively correlated with intentions to leave the unit, organization or the entire profession. Also, Price\& Reichert, (2017)mentioned that the nurse manager is a key in ensuring the retention of nurses long enough to improve the nursing profession and maintain positive working environments and conditions.

\section{Conclusions}

In the light of the study results, the following conclusions can be drawn

- The highest mean score regarding to professionalism behaviors items was related to Self-regulation \& autonomy, competence and continuing education and theory development.

- The highest mean score regarding to job satisfaction items was related to communication \& relationship in the work, followed by The working conditions.

- Factor which affecting the professionalism behavior as perceived by the studied nurse managers were years of experience, salary and moral factor and Social factor\&Psychological factor.

- There was a significant positive correlation between job satisfaction and professional behaviors .

\section{Recommendations}

In the light of the results of this study the following recommendations will be suggested

1- Acquire higher education to maintain nurse managers professionalism and critically to support an encouraging environment for staff nurses to obtain higher degrees of education

2- Develop and implement continues educational programs for nurse managers that will improve the professional behavior of them.

3- Encourage nurse managers continue their selfdevelopment and to realize the potential of their nursing staff by developing professionalism

4- Encourage nurse managers to participate in scientific activities and research.

\section{References}

1- Adıguzel, H., Tanriverdi, D., Ozkan, (2011): Occupational professionalism and the case of nurses as the members of the profession. Journal of Administrative Science, Vol.9, No.2, 235259.

2- Adler, P., \& Kwon, S., (2013): The mutation of professionalism as a contested diffusion process: Clinical guidelines as carriers of institutional change in medicine. Journal of Management Studies, 50(5), 930-962.

3- Atefi, N., Abdullah, K., \& Wong, L., (2016): Job satisfaction of Malaysian registered nurses: a qualitative study. Nursing in critical care, 21(1), 8-17.

4- Atefi, N., Abdullah, K., Wong, L., \&Mazlom, R., (2014): Factors influencing registered nurses perception of their overall job satisfaction: a qualitative study. International nursing review, 61(3), 352-360.

5- Brunges, M., \& Foley-Brinza, C., (2014): Projects for increasing job satisfaction and creating a healthy work environment. AORN journal, 100(6), 670-681.

6- Çelik, S., \&Hisar, F., (2012): The influence of the professionalism behaviour of nurses working in health institutions on job satisfaction. International Journal of Nursing Practice, 18(2), 180-187.

7- Dikmen, Y., Karataş, H., Arslan, G., \& Ak, B., (2016): The level of professionalism of nurses working in a hospital in Turkey. Journal of caring sciences, 5(2), pp95.

8- Drennan J., (2012): An evaluation of management and leadership outcomes using a retrospective pre-test design. Journal of Nursing Management 20 (1), 102-112.

9- Eneh V., Vehvilainen-Julkunen K., \& Kvist T., (2012): Nursing leadership practices as 
perceived by Finnish nursing staff: high ethics, less feedback and rewards. Journal of Nursing Management 20, 159-169.

10- Ghadirian, F., Salsali, M., \&Cheraghi, M., (2014): Nursing professionalism: An evolutionary concept analysis. Iranian journal of nursing and midwifery research, 19(1), 1.

11- Grant, A., (2014): The evolution of professional coaching and coaching psychology. In Handbook of coaching psychology (pp. 4359).

12- Hampton G., \& Hampton D., (2004): Relationship of professionalism, rewards, market orientation and job satisfaction among medical professions: The case of certified nursemidwives. Journal of Business Research; 57: 1042-1053.

13- Holmberg, C., Caro, J., \&Sobis, I., (2018): Job satisfaction among Swedish mental health nursing personnel: Revisiting the two-factor theory. International journal of mental health nursing, 27(2), 581-592.

14- Hwang, J., Lou, F., Han, S., Cao, F., Kim, W., \& Li, P., (2009): Professionalism: the major factor influencing job satisfaction among Korean and Chinese nurses. International nursing review, 56(3), 313-318.

15- Irvine F., Lloyd D, Jones P., Allsup D., Kakehashi C., (2007) : Lost in translation? Undertaking transcultural qualitative research. Nurse Res 14: 46-59.

16- Keys Y., (2014): looking ahead to our next generation of nurse leaders: generation $\mathrm{X}$ nurse manager. Journal of Nursing Managementpp22, 97-105.

17- Lane A., Eser J., Holte B., Anne M., (2010): Study of nurse faculty job satisfaction in community colleges in Florida. Teaching and Learning in Nursing, 5: 16-26.

18- Lu H., White, E., \& Bariball L., (2005): Job satisfaction among nurses: A literature review. International Journal of Nursing Studies 2005; 42: 211-227.

19- Miller, B., Adams, D., \&Beck L., (1993): A behavioral inventory for professionalism in nursing. Journal of Professional Nursing 1993; 9: 290-295.

20- Mohamed, F., (2001): The Relationship between absenteeism and job satisfaction among nurses in Assuit University Hospital, unpublished master degree thesis 82-83.

21- Palmer S., (2014): Nurse retention and satisfaction in Ecuador: implication for nursing administration. Journal of Nursing Management 22, 89-96.
22- Price, S., \& Reichert, C., (2017): The importance of continuing professional development to career satisfaction and patient care: meeting the needs of novice to mid-to latecareer nurses throughout their career span. Administrative Sciences, 7(2), 17.

23- Pool, I., Poell, R., \& Ten Cate, O., (2013). Nurses' and managers' perceptions of continuing professional development for older and younger nurses: A focus group study. International journal of nursing studies, 50(1), 34-43

24- Tanang, H., \& Abu, B., (2014): Teacher Professionalism and Professional Development Practices in South Sulawesi, Indonesia. Journal of curriculum and teaching, 3(2), 25-42.

25- Watkins D., (2011): The influence of Masters education on the professional lives of British and German nurses and the further professionalization on nursing. Journal of Advanced Nursing 67 (12), 2605-2614.

26- Watson R., (2006): Is there a role for higher education in preparing nurses? Nurse Education Today 26, 622-626.

27- Whitman, D., Van Rooy, D., \& Viswesvaran, C., (2010): Satisfaction, citizenship behaviors, and performance in work units: A meta-analysis of collective construct relations. Personnel psychology, 63(1), 41-81.

28- Weiss, D., Dawis, R., \& Lofquist, L., (1967): Manual for the Minnesota Satisfaction Questionnaire, Minnesota Studies in Vocational Rehabilitation: XII. Minneapolis, MN: University of Minnesota Industrial Relations Center, Work Adjustment Project, 1967.

29- Yarbrough, S., Martin, P., Alfred, D., McNeill, C., (2017): Professional values, job satisfaction, career development, and intent to stay. Nursing Ethics, 24, 675685.doi:10.1177/0969733015623098. 